$43(1) \mid 2014$

Varia

Piura: Universidad de Piura. 2013, 213 pages

\title{
Ofelia Huamanchumo de la Cuba. Encomiendas y cristianización. Estudio de documentos jurídicos y administrativos del Perú. Siglo XVI
}

Caroline Cunill

(2) OpenEdition

Journals

Edición electrónica

URL: http://journals.openedition.org/bifea/4411

DOI: 10.4000/bifea.4411

ISSN: 2076-5827

Editor

Institut Français d'Études Andines

Edición impresa

Fecha de publicación: 1 mayo 2014

Paginación: 175-176

ISSN: 0303-7495

Referencia electrónica

Caroline Cunill, «Ofelia Huamanchumo de la Cuba. Encomiendas y cristianización. Estudio de documentos jurídicos y administrativos del Perú. Siglo XVI », Bulletin de I'Institut français d'études andines [En línea], 43 (1) | 2014, Publicado el 08 mayo 2014, consultado el 06 noviembre 2020. URL : http:// journals.openedition.org/bifea/4411; DOI : https://doi.org/10.4000/bifea.4411

\section{(c) (i) $\odot$ EY}

Les contenus du Bulletin de l'Institut français d'études andines sont mis à disposition selon les termes de la licence Creative Commons Attribution - Pas d'Utilisation Commerciale - Pas de Modification 4.0 International. 


\title{
Ofelia Huamanchumo de la Cuba. Encomiendas y cristianización. Estudio de documentos jurídicos y administrativos del Perú. Siglo XVI. Piura: Universidad de Piura, 2013, 213 pp.
}

\begin{abstract}
En Encomiendas y cristianización. Estudio de documentos jurídicos y administrativos del Perú. Siglo XVI, Ofelia Huamanchumo de la Cuba analiza cuatro tipos de fuentes jurídico-administrativas elaboradas en el Perú durante el periodo colonial: las cartas de petición, las memorias, las instrucciones de visita y, finalmente, las visitas. Aquel objeto de estudio no solo se justifica por la escasa producción científica dedicada a la diplomática indiana, desde los trabajos de José Joaquín Real Díaz (1970) y de Antonia Heredia (1985), sino también por la adopción de una metodología interdisciplinaria, en la que el análisis lingüístico va de la mano con la preocupación histórica. En efecto, como lo plantea la autora desde la introducción, la forma y el contenido de los discursos jurídicos coloniales han de entenderse como «enunciación única y particular» y expresión de distintas «tradiciones textuales», pero también como resultado de los procesos históricos peculiares que condicionaron su surgimiento. El título se refiere, por lo tanto, a este doble enfoque: por un lado, el marco interpretativo en el que se pensaba y se escribía en el Perú del siglo XVI, esto es, encomiendas y cristiandad y, por otro lado, el interés filológico por los documentos jurídicos y administrativos producidos en este peculiar contexto histórico.
\end{abstract}

La principal originalidad del trabajo consiste, por consiguiente, en desplazar el objeto tradicional de la filología: este, en efecto, deja de ser las crónicas coloniales, sobre las que ya existe una abundante bibliografía, para pasar a ser el texto jurídico-administrativo, al que muy pocos estudios están dedicados hasta la fecha de hoy. Para llevar a cabo este análisis, Ofelia Huamanchumo se apoya en lo mejor de dos tradiciones historiográficas, de las que realiza una sugerente síntesis alrededor de su propio objeto de estudio. Nos referimos a la filología romana representada por Wulf Oesterreicher, Johannes Kabatek, Jens Lüdtke o Peter Kosh y, por otra parte, a la historia peruana representada, a su vez, por investigadores como Rolena Adorno, Franklin Pease, Francisco Cuenca Boy, Carmen Bernand o José de la Puente Brunke. La autora tampoco descarta la renovada historia del derecho indiano, puesto que hace acertadas referencias a los trabajos de Thomas Duve, Renzo Honores o Beatriz Bernal para esclarecer el sentido de los conceptos teórico-legales presentes en los textos coloniales.

En este sentido, la obra se inserta en una corriente historiográfica que convierte el texto jurídico de tradición hispanoamericana en objeto de estudio lingüístico e histórico, y cuyos principales exponentes Ofelia Huamanchumo no deja de citar - pensamos en Rodolfo Cerrón-Palomino, Andreas Wesch, Eva María Bravo García, Rafael Cano Aguilar, Patricia Correa, Carlos Garatea o José Luis Riverola-. Y es que, además de la ya mencionada dimensión interdisciplinaria, uno de los máximos logros de Encomiendas y cristianización. Estudio de documentos jurídicos y administrativos del Perú radica precisamente en el carácter exhaustivo de la 
bibliografía que maneja su autora. En efecto, hoy en día la producción científica es tan abundante como dispersa, de manera que resulta cada vez más difícil abarcarla en un intento de completitud sin desvirtuarla de su esencia. No obstante, Ofelia Huamanchumo de la Cuba no solo utiliza en su análisis a numerosas corrientes historiográficas, sino que consigue darles sentido, creando (o más bien recreando) vínculos entre Europa y América, entre la Edad Media y la Edad Moderna, entre las tradiciones indígenas y las hispanas, entre la lingüística y la ciencia jurídica.

En esta complicada apuesta, el hilo conductor que guía la obra es una moderna concepción de la historia, entendida como marco y con-texto dinámico y global, en el que circulan las personas y los objetos, las ideas y las palabras de un espacio a otro, de un tiempo a otro, renovándose sin cesar el sentido y el valor que la humanidad dio y está dando a las cosas y al mundo en este continuo andar. A fin de cuentas, la trayectoria de la autora tal vez sea el reflejo mismo de esta historia en movimiento, ya que no resulta anodino que, habiendo recibido una formación académica en Perú (donde se publica el presente libro), Ofelia Huamanchumo haya realizado su tesis de doctorado (de la que deriva dicha obra) en Alemania, lo que probablemente facilitó la elaboración de esa feliz síntesis de diversas tradiciones historiográficas en un texto original. Solo queda por sugerir y esperar una próxima publicación centrada en las probanzas de méritos y servicios, a las que la academia dedicó relativamente poca atención desde el conocido artículo de Murdo MacLeod (1998) y que el presente libro solo aborda tangencialmente en el capítulo sobre las cartas de petición, puesto que estas constituían la parte inaugural de las probanzas. 